\title{
P037. Headache in multiple sclerosis: prevalence and clinical features in a case control-study
}

\author{
Rossana Terlizzi ${ }^{1 *}$, Elena Merli', Elena Buccellato ${ }^{1}$, Giulia Giannini ${ }^{1}$, Valentina Favoni ${ }^{1}$, Giulia Pierangeli ${ }^{1}$, \\ Fabrizio Salvi ${ }^{2}$, Pietro Cortelli ${ }^{1}$, Sabina Cevoli ${ }^{1}$ \\ From Abstracts from the 1st Joint ANIRCEF-SISC Congress \\ Rome, Italy. 29-31 October 2015
}

\section{Background}

Ten cross-sectional studies have examined a potential association between migraine and multiple sclerosis (MS); some of them found an association between the two conditions $[1,2]$ while five studies did not [3]. The overall incidence of migraine in MS patients ranges from $4 \%$ to $64 \%$, but very few controlled studies has been conducted $[4,5]$.

\section{Objective}

The aim of the present study was to investigate the prevalence and the clinical features of different types of headaches in subjects affected from MS respect to a control group.

\section{Methods}

One hundred and fifty adults $(\mathrm{F} / \mathrm{M}=98 / 52$; mean age 40 years) with a diagnosis of MS and 150 sex and agematched controls ( $\mathrm{F} / \mathrm{M}=101 / 49$; mean age 40 years) from the general population were evaluated by means of an ad hoc semi-structured interview according to the International Classification Headache Disorders (ICHD-3-beta) criteria. All subjects filled out validated questionnaires about fatigue, Fatigue Severity Scale (FSS) and Modified Fatigue Impact Scale (MFIS). The $\chi 2$ and Kruskal-Wallis tests were used when appropriate.

\section{Results}

The two groups differed significantly for education level and employment. Among the 150 patients with MS, 1 $(0.7 \%)$ presented a radiologically isolated syndrome (RIS), $17(11.3 \%)$ a clinically isolated syndrome (CIS), 20 (13.3\%)

\footnotetext{
* Correspondence: rossanaterlizzi@gmail.com

'Department of Biomedical and NeuroMotor Sciences (DIBINEM) Alma Mater Studiorum, University of Bologna, IRCCS Institute of Neurological Sciences of Bologna, Bologna, Italy

Full list of author information is available at the end of the article
}

a primary progressive form (PPMS), 96 (64\%) a relapsing remitting form (RR), and $16(10.7 \%)$ a secondary progressive form (SPMS). Headache was reported by 80 (53.3\%) MS cases and 71 controls (47.3\%), ( $\mathrm{p}=0.356)$; migraine was reported by $47(31.33 \%)$ cases and $51(34 \%)$ controls, tension-type headache was present in 21 (14\%) MS affected vs $14(9.33 \%)$ controls $(\mathrm{p}=0.245)$. The simultaneous presence of migraine and tension-type headache was statistically higher $(\mathrm{p}=0.002)$ in MS $(28.8 \%)$ compared to controls (8.5\%). Women with MS presented a low correlation between migraine and menstruation compared to controls while migraine normally improves during pregnancy as much as in controls $(\mathrm{p}=0.65)$. The preliminary analysis of FSS and MFIS scores showed that fatigue resulted overall higher in MS patients with or without headache.

\section{Conclusions}

Although MS patients showed a high prevalence of headache, particularly migraine, the overall prevalence was not significantly different compared to the general population. Fatigue, a well-known symptom of MS, seems to be primarily correlated to disease and poorly influenced by the presence of headache. Moreover, women with MS and migraine should be reassured regarding the possibility that their headache could improve during pregnancy as in those without MS.

Written informed consent to publication was obtained from the patient(s).

\section{Authors' details}

${ }^{1}$ Department of Biomedical and NeuroMotor Sciences (DIBINEM) Alma Mater Studiorum, University of Bologna, IRCCS Institute of Neurological Sciences of Bologna, Bologna, Italy. ${ }^{2}$ RCCS Institute of Neurological Sciences of Bologna, Bologna, Italy.
SpringerOpen ${ }^{\circ}$

C 2015 Terlizzi et al. This is an Open Access article distributed under the terms of the Creative Commons Attribution License (http:// creativecommons.org/licenses/by/4.0), which permits unrestricted use, distribution, and reproduction in any medium, provided the original work is properly cited. The Creative Commons Public Domain Dedication waiver (http://creativecommons.org/publicdomain/ zero/1.0/) applies to the data made available in this article, unless otherwise stated. 


\section{References}

1. Kister I, Caminero AB, Herbert J, Lipton RB: Tension-type headache and migraine in multiple sclerosis. Curr Pain Headache Rep 2010, 14(6):441-8.

2. Vacca G, Marano E, Brescia Morra V, Lanzillo R, De Vito M, Parente E, Orefice G: Multiple sclerosis and headache co-morbidity. A case-control study. Neurol Sci 2007, 28(3):133-5.

3. Nicoletti A, Patti F, Lo Fermo S, Liberto A, Castiglione A, Laisa P, Garifoli A, La Naia F, Maimone D, Sorbello V, Contrafatto D, Zappia M: Headache and multiple sclerosis: a population-based case-control study in Catania, Sicily. Cephalalgia 2008, 28:1163-1169.

4. D'Amico D, La Mantia L, Rigamonti A, Usai S, Mascoli N, Milanese C, Bussone G: Prevalence of primary headaches in people with multiple sclerosis. Cephalalgia 2004, 24:980.

5. Gelfand AA, Gelfand JM, Goadsby PJ: Migraine and multiple sclerosis: Epidemiology and approach to treatment. Mult Scler Relat Disord 2013, 2(2):73-9.

doi:10.1186/1129-2377-16-S1-A83

Cite this article as: Terlizzi et al:: P037. Headache in multiple sclerosis: prevalence and clinical features in a case control-study. The Journal of Headache and Pain 2015 16(Suppl 1):A83.

\section{Submit your manuscript to a SpringerOpen ${ }^{\mathcal{O}}$ journal and benefit from:}

- Convenient online submission

- Rigorous peer review

- Immediate publication on acceptance

- Open access: articles freely available online

- High visibility within the field

- Retaining the copyright to your article

Submit your next manuscript at $\gg$ springeropen.com 